\title{
Site fidelity, residence time and movements of red snapper Lutjanus campechanus estimated with long-term acoustic monitoring
}

\author{
Darin T. Topping ${ }^{1,2, *}$, Stephen T. Szedlmayer ${ }^{1}$ \\ ${ }^{1}$ Department of Fisheries and Allied Aquacultures, Auburn University, Fairhope, Alabama 36532, USA \\ ${ }^{2}$ Senator George G. Kirkpatrick Marine Laboratory, Fish and Wildlife Research Institute, Cedar Key, Florida 32625, USA
}

\begin{abstract}
Residence time, site fidelity and movements for red snapper Lutjanus campechanus (Lutjanidae) were estimated from long-term telemetry monitoring (December 2005 to June 2010) at 6 sites (1 natural and 5 artificial reefs) in the northeastern Gulf of Mexico. Each site consisted of an array of 5 receivers, with 1 at the center reef site and 4 receivers placed $1100 \mathrm{~m}$ north, south, east and west of center ( $2 \mathrm{~km}$ radius detection area). Throughout the study, a stationary control transmitter was located $400 \mathrm{~m}$ south of the center receiver at each site to estimate changes in detection rates from environmental factors. These receiver arrays enabled fishery independent estimations of fishing mortality, natural mortality and emigration. Event analysis was used to estimate site fidelity and residence, based on right-censoring fishing and natural mortality. Median residence time was $542 \mathrm{~d}$, ranging from 1 to $1099 \mathrm{~d}$, with $72 \%$ of fish staying at least $1 \mathrm{yr}$ at the site. Some fish $(n=12)$ showed seasonal and directed movements to other sites (up to $8 \mathrm{~km}$ away) and returned to original sites up to 7 mo later. Diel movements away from the structure tended to occur at night. Site fidelity and residence times of red snapper in the present study were greater than in any previous study and show the importance of artificial reefs for this species.
\end{abstract}

KEY WORDS: Site fidelity · Acoustic telemetry $\cdot$ Seasonal movements $\cdot$ Red snapper $\cdot$ Artificial reefs

\section{INTRODUCTION}

Red snapper Lutjanus campechanus occur over natural reef structure in the Gulf of Mexico (GOM; Camber 1955, Moseley 1966, Beaumariage 1969, Fable 1980), and also have a close association with artificial habitat (Szedlmayer \& Shipp 1994, Szedlmayer 1997, Watterson et al. 1998, Peabody 2004, Szedlmayer \& Schroepfer 2005). Although approximately 10000 to 20000 artificial habitats have been deployed in the northern GOM, which may provide benefits of increased food and shelter to red snapper, stocks are still considered overfished (Minton \& Heath 1998, Schirripa \& Legault 1999, SEDAR 2005, Shipp \& Bortone 2009). In contrast, smaller red snapper $(<400 \mathrm{~mm}$ total length [TL]) were the most numerically abundant fish species on both natural and artificial habitats off Alabama, and occur in high numbers at GOM oil rigs (Gitschlag et al. 2003, Lingo \& Szedlmayer 2006, Wells \& Cowan 2007, Gallaway et al. 2009). Despite the fact that only a small proportion of natural reef structure exists in the northern GOM (compared to sand and mud habitat), these artificial structures may significantly increase 'red snapper' habitat and probably helped establish a significant red snapper fishery (Parker et al. 1983, Schroeder et al. 1988, Dufrene 2005, Szedlmayer 2007, Shipp \& Bortone 2009, Gallaway et al. 2009). Although these artificial structures may provide suitable habitat for red snapper, fishing mortality at these structures may offset any benefits provided by these habitats (Bohnsack 1989, Strelcheck et al. 2007). Benefits of reef structure to red snapper can be addressed with long-term information on site fidelity, 
residence times and movement patterns around natural and artificial structures.

The residency of red snapper Lutjanus campechanus on natural and artificial structures has been examined by several methods, with varying results. Early studies examined the distribution of red snapper catches relative to habitat type, depth and season (Camber 1955, Moseley 1966, Bradley \& Bryan 1975), and more recent studies have used mark-recapture (Beaumariage 1969, Fable 1980, Szedlmayer \& Shipp 1994, Watterson et al. 1998, Patterson et al. 2001, Patterson \& Cowan 2003, Diamond et al. 2007, Strelcheck et al. 2007) and ultrasonic telemetry (Szedlmayer 1997, Peabody 2004, Szedlmayer \& Schroepfer 2005, Schroepfer \& Szedlmayer 2006) to estimate site fidelity and movements. For the most part, these studies indicate red snapper show some affinity to both natural and artificial structures, but estimates of site fidelity and residence times seem to vary by methods (mark-recapture vs. telemetry), habitat type (e.g. small artificial reefs, oil-gas platforms and natural reefs), hurricanes, transmitter detection range, fish size and study length (Diamond et al. 2007, Gallaway et al. 2009).

Recent mark-recapture studies of relatively small red snapper (mean: <400 mm TL) off Alabama obtained different results even with similar methods (Patterson \& Cowan 2003, Strelcheck et al. 2007). Patterson \& Cowan (2003) estimated site fidelity at approximately $25 \% \mathrm{yr}^{-1}$ from declines in captures at tagging sites (minus an assumed natural mortality rate of $M=0.1$ and no fishing mortality). Strelcheck et al. (2007) used the same method, tagged fish at similar habitats and obtained site-fidelity rates of around $50 \% \mathrm{yr}^{-1}$. Mark-recapture studies that attempt to estimate residency and movements must rely on the recapture of tagged fish (fishery dependent), the accuracy of the reported information (location and date) and the willingness of fishers to report a tag (Green et al. 1983). All of these factors may decrease the reliability of residency estimates. In addition, mark-recapture studies lack information on timing of movements, and it is difficult to detect movement away from and back to the original release site.

Recently, ultrasonic telemetry methods have greatly improved the spatial and temporal resolution in red snapper movement studies and removed almost all dependence on fishery returns (Szedlmayer 1997, Peabody 2004, Szedlmayer \& Schroepfer 2005). Residence times of red snapper ranged from 17 to $597 \mathrm{~d}$ at artificial habitats off Alabama, using telemetry to relocate or continuously monitor individ- ual fish, with a median residence time of $373 \mathrm{~d}$ and site fidelity of $50 \% \mathrm{yr}^{-1}$ from event analysis (Szedlmayer 1997, Szedlmayer \& Schroepfer 2005, Schroepfer \& Szedlmayer 2006). Peabody (2004) also used ultrasonic telemetry to monitor the residency and movements of small red snapper $(<450 \mathrm{~mm} \mathrm{TL} ; \mathrm{n}=$ 125) around oil-gas platforms off Louisiana, with $78 \%$ detected from 1 to $202 \mathrm{~d}$ after release, and only 13 of the detected fish moved away from the original release location after 6 mo. After $70 \mathrm{~d}$, however, there was only a $50 \%$ probability of detection of these fish at the release site, possibly due to transmitter failure and low detection range ( $<75 \mathrm{~m}$ due to thermocline). Based on these results, Westmeyer et al. (2007) concluded that red snapper had high short-term fidelity and low long-term fidelity.

Both ultrasonic-telemetry and tag-recapture studies have estimated residence times over a year with site-fidelity estimates $>50 \% \mathrm{yr}^{-1}$. These previous tagging and telemetry studies have only addressed the movements and residency of smaller fish $(<500 \mathrm{~mm}$ TL), with the exception those by Szedlmayer \& Schroepfer (2005) and Schroepfer \& Szedlmayer (2006). Red snapper can attain sizes up to $1 \mathrm{~m}$ or more, so questions still remain on the residency time of larger red snapper (Szedlmayer \& Shipp 1994, Wilson \& Nieland 2001). In addition, information is still needed on long-term seasonal and diel movements around natural and artificial habitats.

Red snapper appear to move away from artificial structures at night (Peabody 2004, Szedlmayer \& Schroepfer 2005, Topping 2009). This may be in response to more feeding over open habitat prey types with the darkness providing predation protection or that certain prey types were more active at night (Ouzts \& Szedlmayer 2003, McCawley \& Cowan 2007). No other studies have examined diel patterns of movement, and further studies are needed to help clarify the importance of different habitats for this species.

Emigration from reef structures has been attributed to hurricanes (Watterson et al. 1998, Patterson et al. 2001) and cold fronts (Moe 1963, Moseley 1966, Bradley \& Bryan 1975). These studies that attributed increased movements to hurricanes were based on a greater dispersal of recaptures after storm events, but could not examine the exact point when fish emigrated. Early studies also suggested an inshoreoffshore movement for red snapper presumed to be related to changes in temperature or cold fronts, but were only based on seasonal distribution of fishery catches. Resolving some of the factors that may trigger red snapper movements (emigration and immi- 
gration) at both artificial and natural habitats would help determine why these fish are associated with these structures.

In the present study, long-term ( $>3 \mathrm{yr}$ ) telemetry monitoring methods were used to assess site fidelity, residency and movements of red snapper at artificial habitat sites and a natural habitat site. Strategically placed remote telemetry receivers and long-term transmitters ( $\sim 5 \mathrm{yr})$ were used to assess these aspects of red snapper ecology. In addition, diel and seasonal movement patterns were examined along with the environmental factors that may have influenced these behaviors.

\section{MATERIALS AND METHODS}

\section{Study area}

The study sites were located 20 to $30 \mathrm{~km}$ south of Mobile Bay, Alabama, USA, an area that includes numerous artificial habitats (>10 000) and a few natural rock-reef habitats (Schroeder et al. 1988, Minton \& Heath 1998). Red snapper were tagged on 1 natural and 5 artificial habitats. Artificial habitats included a pipeline covered with a concrete mat (Site A1 in Fig. 1), a 15 m sunken barge (A2), a $4.4 \times 1.3 \times$ $1.2 \mathrm{~m}$ steel metal cage (A3), an M-60 army tank (A4) and a steel-frame pyramid (A5). The natural habitat (N1) was composed of a $20 \mathrm{~m}$ long drowned river bed ( $\sim 1 \mathrm{~m}$ relief), with undercut banks lined with tree stumps (Fig. 1). The depths of the sites ranged from 20 to $30 \mathrm{~m}$.

\section{Fish tagging}

Large red snapper (>500 mm TL) were captured at the selected habitats via hook and line. Fish were brought on board the research vessel, placed in a 701 container of seawater containing MS-222 (150 mg l-1) and quickly anesthetized to Level 4 (Summerfelt \& Smith 1990). Once sedated, the fish were temporarily removed from the anesthetic and an ultrasonic transmitter was implanted within the peritoneal cavity through a small $(18 \mathrm{~mm}$ ) vertical incision made with a No. 11 scalpel slightly above the ventral midline, and sutured with plain gut (Ethicon, No. 2, 3.5 metric). Also, an internal anchor tag (Floy) was inserted into the incision before it was sutured. Sterile surgical methods and betadine were used throughout the procedure. After surgery, the fish were released after a short ( 1 $\mathrm{min})$ period of recovery at the surface (when fin and gill movements were observed). Fish were released at the capture site by lowering fish to the bottom with a weighted line with an inverted

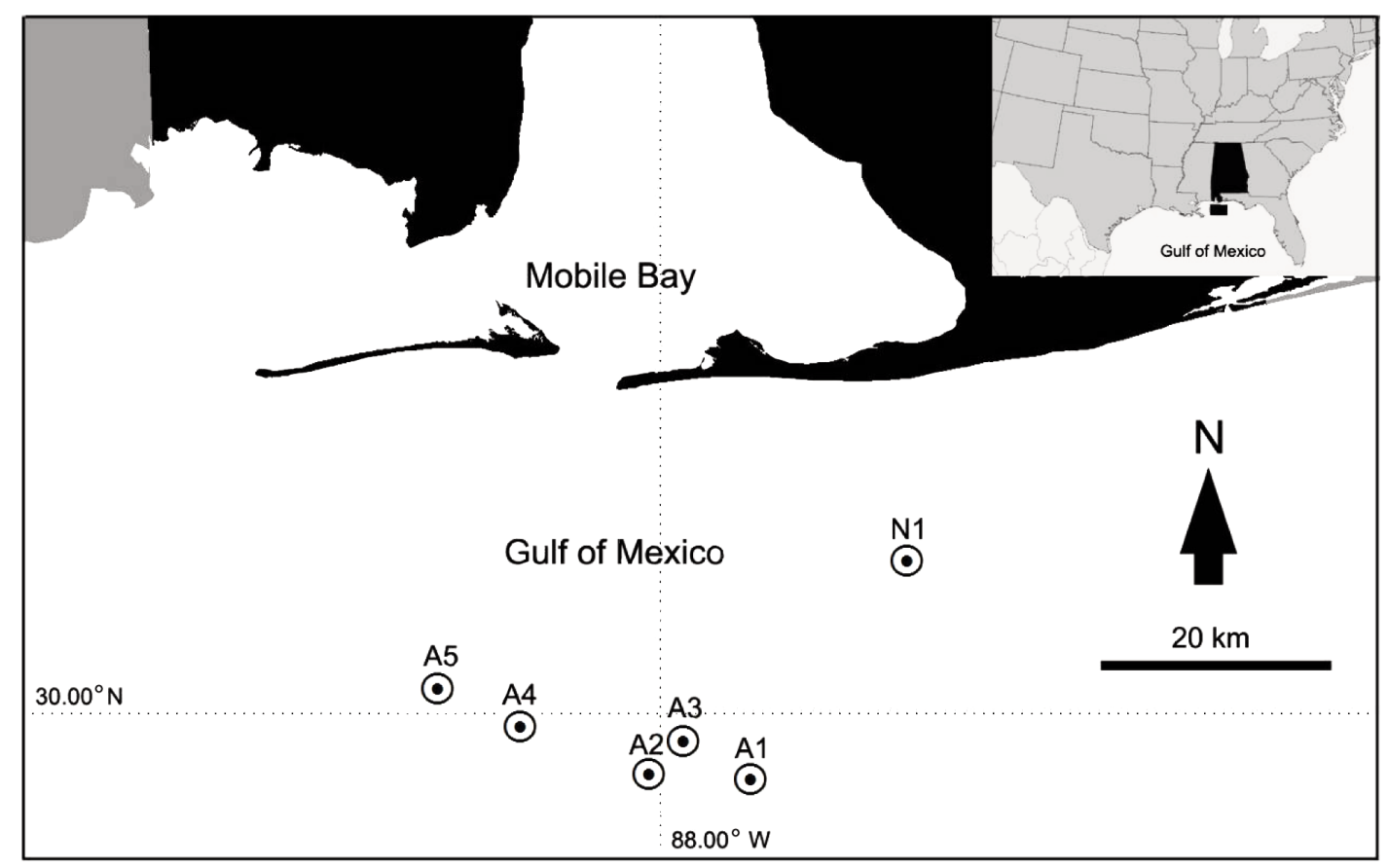

Fig. 1. Location of study sites in the northeast Gulf of Mexico. Inset in upper right shows Gulf of Mexico and study area (black box) offshore Alabama (black state), USA 


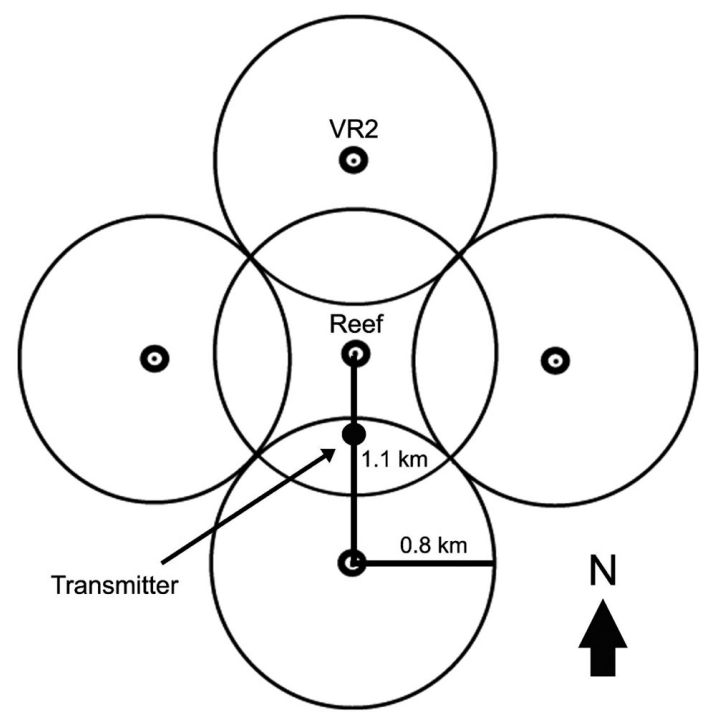

Fig. 2. Design of receiver array (Vemco VR2) for each site, with 1 receiver at the reef and 4 others surrounding the reef, $1.1 \mathrm{~km}(0.42 \mathrm{~km}$ for Sites A4 and A5) away to the north, south, east and west. Circles represent detection range of $0.8 \mathrm{~km}$ ( $0.3 \mathrm{~km}$ for Sites A4 and A5). A stationary control transmitter was placed $400 \mathrm{~m}$ south of the reef $(150 \mathrm{~m}$ for Sites A4 and

A5). Sites A4 and A5 used Sonotronics SUR-1 receivers
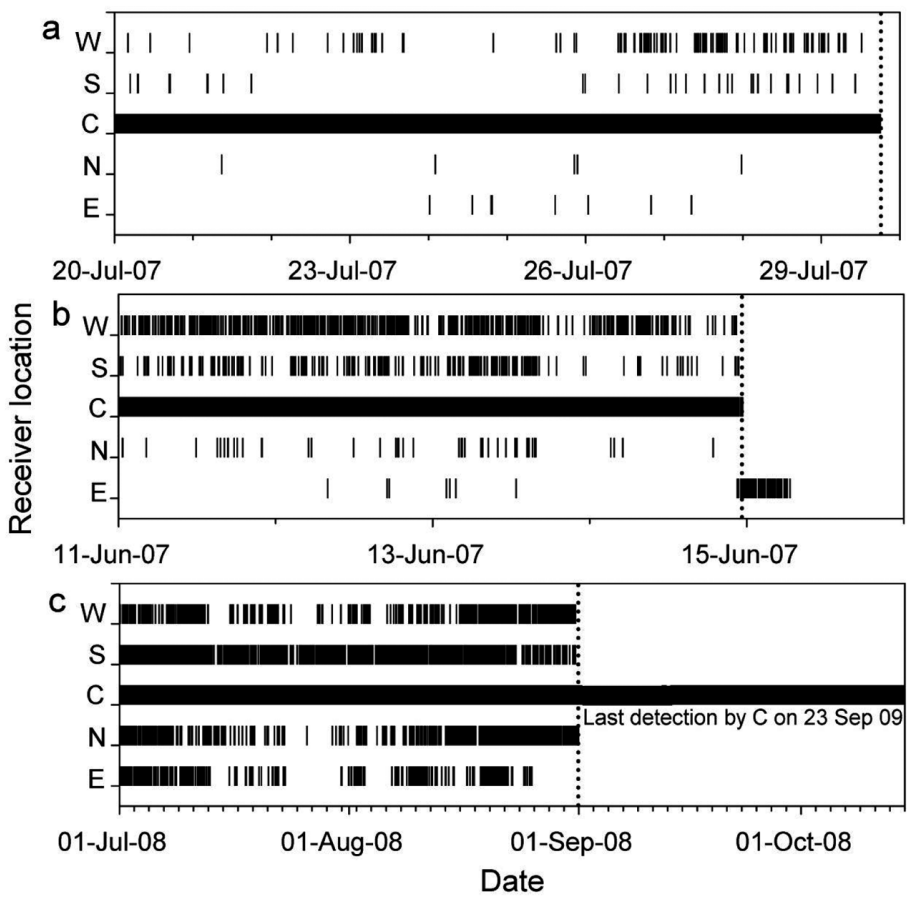

Fig. 3. Lutjanus campechanus. Detection plots showing examples of the detection patterns from fish experiencing (a) fishing mortality, (b) emigration, or (c) natural mortality events. Each plot shows a portion of the overall detections of a single fish by the center $(\mathrm{C})$, north $(\mathrm{N})$, south $(\mathrm{S})$, east $(\mathrm{E})$ and west $(\mathrm{W})$ receivers at the release site. Vertical dotted lines: an event (mortality or emigration) barbless hook that was attached to the fish's lower jaw. Upon retrieval of the weighted line the fish were released at depth near the reef site.

Two types of transmitters were used in the present study; individually coded Vemco transmitters (V166L-R64K; code intervals: 20 to $69 \mathrm{~s}, 16 \times 94 \mathrm{~mm}$; battery life: 6 yr) were used at sites with Vemco VR2 receivers (A1, A2, A3, N1), and coded Sonotronics transmitters (CT-05-48, $16 \times 79$ mm; battery life: $4 \mathrm{yr}$ ) were used at sites where Sonotronics SUR-1 receivers were deployed (A4, A5).

\section{Continuous remote monitoring}

An underwater acoustic receiver array was deployed at each site that included 5 separate omnidirectional receivers (Vemco VR2 or Sonotronics SUR) moored near the bottom ( 5 $\mathrm{m})$. For each array, 1 receiver was located at the release site (center, C) and the other 4 were placed at $1100 \mathrm{~m}$ (VR2) or $420 \mathrm{~m}$ (SUR) to the north $(\mathrm{N})$, south (S), east (E), or west (W) of the center (Fig. 2). Receivers placed at $1100 \mathrm{~m}$ (or $420 \mathrm{~m}$ ) away from the center receiver were predicted to result in complete detection of the fish within a $\sim 2 \mathrm{~km}$ (or $1 \mathrm{~km}$ ) radius of the release site (Szedlmayer \& Schroepfer 2005). All receivers were coated with a copper-based antifouling paint to prevent possible signal occlusion due to biofouling (Heupel et al. 2008).

Detections of fish by these arrays were used to determine if a fish was caught (fishing mortality), died (natural mortality), or emigrated (Fig. 3). Fishing mortality was estimated from both the tag returns by fishers and from the presence (or absence) data recorded by the remote receivers. For example, a fishing mortality was identified by a detection pattern that would show consistent, continuous detections at the center site, followed by a sudden loss of detections at time of capture (last detected by center receiver). Emigration was shown as a decrease in detections of a fish at the center site followed by an increase in detections at a surrounding receiver prior to complete detection loss. A natural mortality was identified when a fish stopped being detected at any outside receiver but was still detected by the center receiver. This natural mortality pattern resulted from a lack of fish movement and a decrease in detection range from a transmitter that was lying on the bottom. The estimates of natural and fishing mortality were necessary to accurately assess 
site fidelity and residence time with event analysis (Schroepfer \& Szedlmayer 2006). Each site was periodically surveyed for tagged fish, using SCUBA aided by an underwater hand-held receiver (Sonotronics) to locate swimming fish with transmitters and dead fish (i.e. tags laying on the bottom). To increase the probability of tag returns by fishers, a tag return reward of USD 50 to 150 was advertised via internet fishing forums, posters distributed at local tackle stores and marinas, and newspaper coverage of the project.

\section{Detection rate and range validation}

A stationary control transmitter was placed $400 \mathrm{~m}$ (VR2) or $150 \mathrm{~m}$ (SUR) south of the center location at each site to estimate changes in detection range throughout the study period, and enabled contrasts between movements and mortality (Figs. 2 \& 3; Topping 2009). This design also helped to account for possible environmental effects on detection range and frequency, and interference due to 'signal collisions' of Vemco transmitters when multiple tagged fish were present at a study site. The mean detection range (averaged across sites and days) was based on the percentage of the maximum expected detections of the control transmitter by receivers as distance from the control transmitter increased $(\mathrm{C}=400 \mathrm{~m}, \mathrm{~S}=$ $700 \mathrm{~m}, \mathrm{E}=1170 \mathrm{~m}, \mathrm{~W}=1170 \mathrm{~m}, \mathrm{~N}=1500 \mathrm{~m})$. The maximum expected detections for an individual transmitter was determined from the relation between the number of transmitters present and the detection frequency of individual transmitters. Transmitters were placed next $(<15 \mathrm{~cm})$ to a VR2 receiver (in air), and the total detections of each transmitter were recorded for $1 \mathrm{~h}$ before transmitter number was increased (+1). A Vemco VR60 receiver with an omnidirectional hydrophone was also placed next to the transmitters to audibly verify the number of clear signal transmissions and collisions to ensure that the VR2 was recording properly. The detections of control transmitters at each study site were then compared to the expected detection frequency based on the number of tagged fish present (+ control) at each site and converted to a percent of expected detections. Continuous water temperatures ( $1 \mathrm{~h}$ resolution) were recorded throughout the study by waterproof temperature loggers (Onset HOBO U22 Water Temp Pro v2) moored at each site near the bottom ( 20 to $33 \mathrm{~m})$ and midwater $(\sim 15 \mathrm{~m})$. Receivers were coated in antifouling paint to prevent signal occlusion from biofouling (Heupel et al. 2008).

\section{Residency and site-fidelity estimation}

Residence time was estimated with event analysis, which calculates the survival function $S(t)$, the proportion $(S)$ of fish residing at the site over time $(t)$. Emigration (event) times were analyzed by the product limit method of Kaplan \& Meier (1958). This method allows for right-censoring of fish that have not experienced an event by the time of analysis (fish still present) or were removed by means not related to the events under analysis (i.e. fishing and natural mortalities). The lifetest procedure in the statistical analysis system (SAS) program was used to estimate the Kaplan-Meier (K-M) survival function (Chambers \& Leggett 1989, Allison 1995, Ohta \& Kakuma 2004, Schroepfer \& Szedlmayer 2006). This analysis estimated residence to the site at $t$ assuming fish were released on the same day and examined the entire distribution of emigration and right-censor times. Median residence time is the number of days when only $50 \%$ of the fish still reside at the sites. Site fidelity was defined as the proportion of fish remaining at the sites on Day 365. The K-M survival (residence) function $S(t)$ is defined as the proportion of individuals residing, to $t$ :

$$
\hat{S}(t)=\Pi_{t_{j} \leq t}\left(1-d_{j} / r_{j}\right)
$$

where $t$ is the time over which residence is estimated from the product of the conditional probabilities of residence at each emigration $j, d_{j}$ represents the number of individuals that emigrated and $r_{j}$ represents the number of individuals at risk of an emigration at time $t_{j}$ (Kaplan \& Meier 1958). Variances and $95 \%$ confidence intervals for $\mathrm{K}-\mathrm{M}$ residence estimates were defined by Cox \& Oakes (1984) and Pollock et al. (1989) as:

$$
\begin{gathered}
\operatorname{Var}[\hat{S}(t)]=[\hat{S}(t)]^{2}[1-\hat{S}(t)] / r(t) \\
{[\hat{S}(t)] \pm 1.96[\operatorname{var} \hat{S}(t)]^{1 / 2}}
\end{gathered}
$$

\section{Data analysis}

Residency and site fidelity were estimated based on an event analysis method. The effect of fish size (TL) on residence time was tested with a log-rank test of association within the SAS lifetest procedure (Kalbfleisch \& Prentice 1980). A log-rank test for homogeneity (lifetest procedure) was used to compare between various residence curves (Klein \& Moeschberger 1997). The number of fish emigrating in each season was compared to the null hypothesis of equal proportions of fish emigrating in each season (summer, beginning on 21 June; fall, 23 September; 
winter, 21 December; spring, 21 March) with a likelihood ratio chi-squared test to examine seasonal emigration. A likelihood ratio chi-squared test was also used to test whether equal proportions of fish emigrated from the release site in N, S, E and W directions (Cody \& Smith 2006). These proportions also include directions for fish that relocated to other habitats within the detection range of $N, S, E$, or $W$ receivers at a study site and movement to other study sites.

Estimates of residency and emigration were derived from both Sonotronics and Vemco telemetry data, but, due to differences in technology, only Vemco VR2 receiver data (with V16 transmitters) were used for movement pattern analysis (Sites A1, A2, A3 and N1). To examine periodicity of detections, a fast Fourier transformation (FFT) was applied to a continuous time series of the total number of detections per hour at the center receiver (Peabody 2004, Meyer et al. 2007). A local regression (LOESS procedure, SAS; Cleveland 1979, Cleveland \& Devlin 1988, Cohen 1999) of detection rates at $1 \mathrm{~h}$ intervals was also used to examine diel periodicity of movements. The LOESS procedure can determine the pattern of diel movements away from the center receiver (assuming lower detections when fish are further away) or toward the surrounding receivers (increase in detections on $\mathrm{N}, \mathrm{S}, \mathrm{E}$ and $\mathrm{W}$ receivers) by using a local regression to estimate regression surfaces fitted to data points (total detections per hour) within a chosen neighborhood (smoothing factor) of each value of

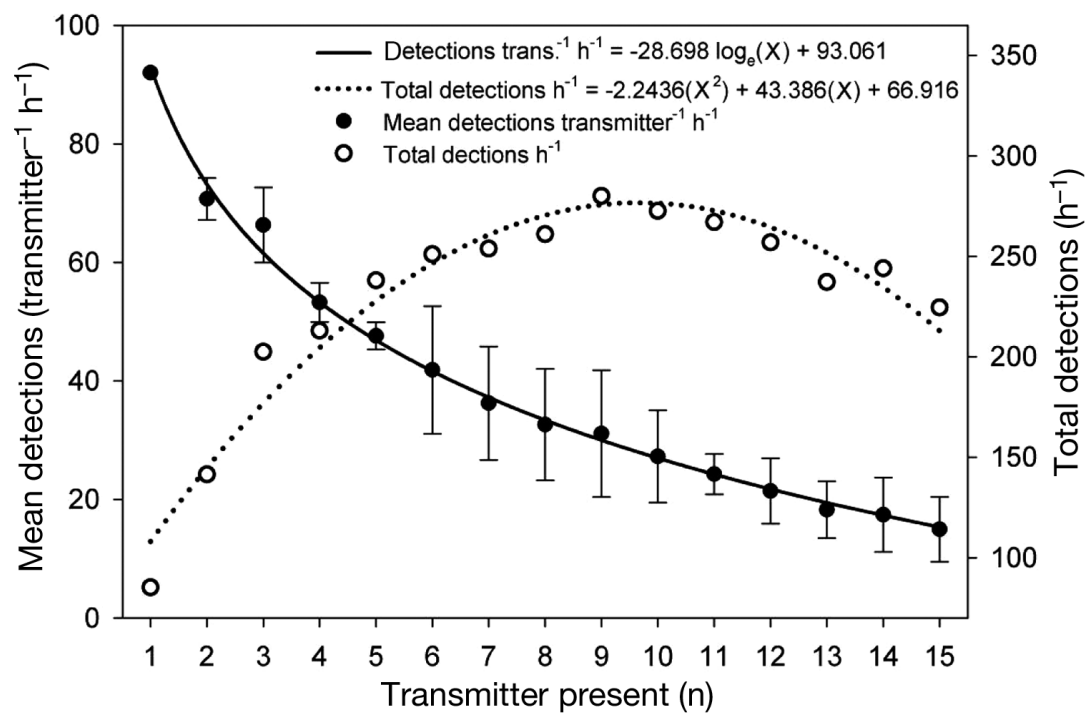

Fig. 4. Comparison of mean detections per transmitter per hour $( \pm \mathrm{SD})$ to number of transmitters present showed a logarithmic negative relation (solid line; $\mathrm{R}^{2}=$ 0.99). Comparison of total detections per hour to transmitter number showed a quadratic relation (dotted line; $\mathrm{R}^{2}=0.95$ ) the independent variable (Cleveland 1979, Cleveland \& Devlin 1988, Cohen 1999, Peabody 2004). The smoothing parameter was determined from the SmoothSelect macro in SAS, which selects the smoothing parameter that yields the smallest Akaike information criterion $\left(\mathrm{AIC}_{\mathrm{C} 1}\right.$ ) statistic (Cohen 1999). The same time series used for the FFT analysis was analyzed with LOESS. Total detections per hour on the center receiver and the combined total detections per hour on outside receivers $(N, S, E, W)$ for fish at a site were obtained each hour over $24 \mathrm{~h}$ diel cycles (00:00 to 23:00 h), with each day of the time series yielding 1 data point for each $1 \mathrm{~h}$ period. The detections on the outside receivers were combined due to fish moving in different directions from the reef. Statistical differences were all considered significant at $\mathrm{p} \leq 0.05$.

\section{RESULTS}

\section{Detection rate and range validation}

Mean detections per transmitter per hour significantly decreased as the number of transmitters present next to a VR2 receiver was increased and was described by a negative logarithmic relation $\left(\mathrm{r}^{2}=\right.$ 0.99, p < 0.0001; Fig. 4). Detections per transmitter per hour decreased from 92 for 1 transmitter present to 15 detections per transmitter per hour when 15 transmitters were present. Total detections per hour increased to a maximum of 280 when 9 transmitters were present, but total detections decreased when $>10$ transmitters were present due to excessive signal collisions $\left(\mathrm{r}^{2}=0.95\right.$; Fig. 4). Based on these results, the maximum number of transmitters at each reef site (at any time) was 10 (fish + control).

The relation between number of fish (transmitters) present and detection rate was used to estimate the maximum detections of the control transmitter expected at each site for each day. A fish was considered present at a particular site only after it was detected a minimum of 5 times at that site on a particular day. The percentage of maximum expected detection rate was estimated from June 2006 to August 2008 over the distances these controls were placed 
away from the C, S, E, W and N VR2s. There were seasonal periods when control transmitter detection rates were reduced below expected rates due to changing environmental conditions that reduced detection ranges (Fig. 5). A logistic relation was predicted from mean percent of maximum expected detections of the control transmitter to receiver distance (Fig. 6; $\mathrm{r}^{2}=0.98, \mathrm{p}=0.03$ ). Mean percent of expected detections at $400 \mathrm{~m}$ was reasonably high (mean \pm SD: $79 \pm 14 \%$; Fig. 6 ), followed by $65 \%$ at $700 \mathrm{~m}$. Detections of the control transmitter were about $25 \%$ lower at the $\mathrm{N} 1$ site at $400 \mathrm{~m}$ than at all other sites, which may be due to shallower $20 \mathrm{~m}$ (N1) versus $30 \mathrm{~m}$ depths (A1, A2, A3).

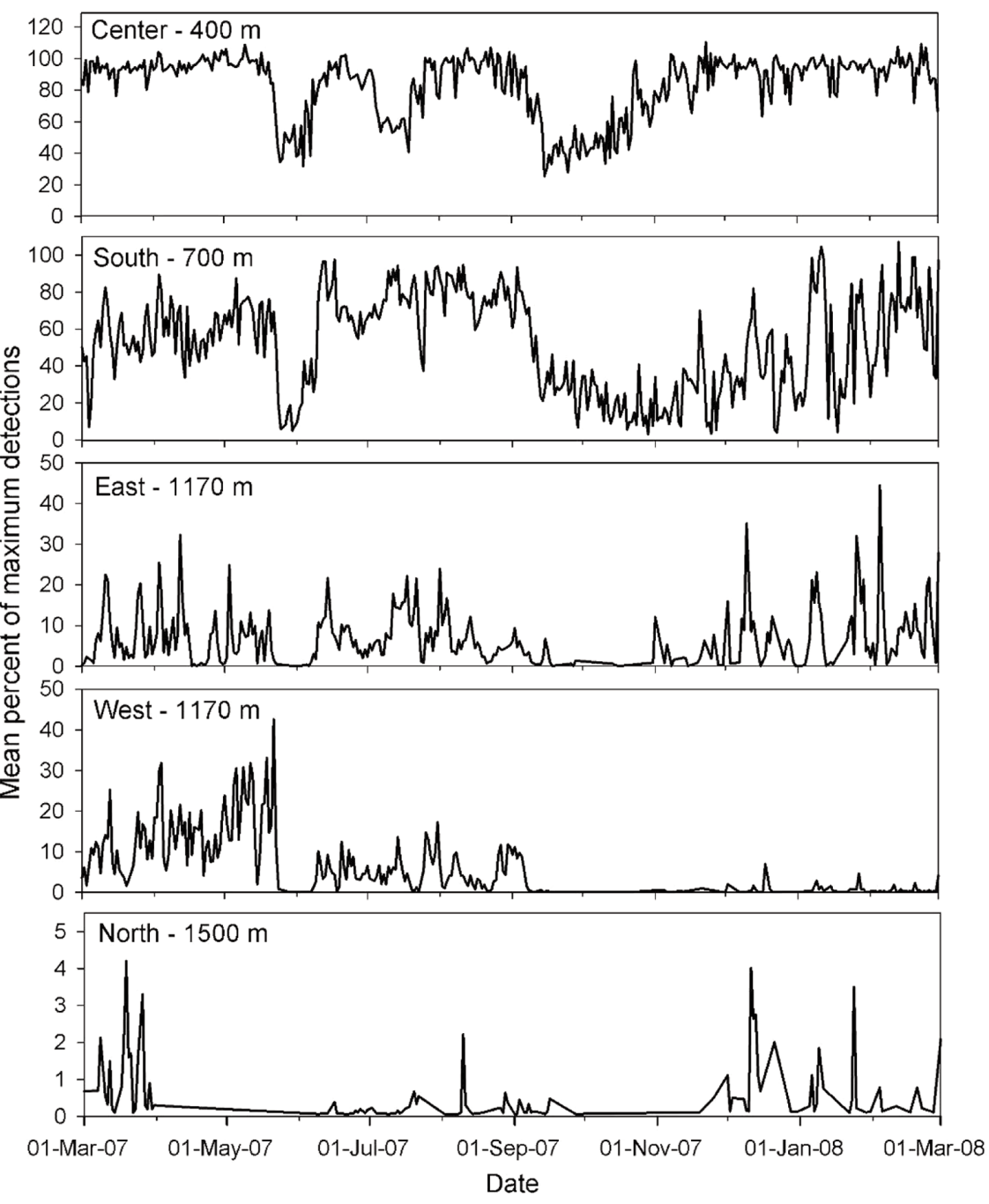

Fig. 5. Mean control transmitter detections at each distance (mean detections of Sites A1, A2 and A3 for center, south, east, west and north VR2s on each date) shown as the mean percent of the maximum expected detections. Expected detections were calculated from the relation of detections per transmitter per hour (see Fig. 4) to number of transmitters (fish) present at a given location. Note: different $y$-axis scales

\section{Residence time and site fidelity}

Red snapper Lutjanus campechanus $(\mathrm{n}=102)$ were monitored at 6 different sites (A1 to A5, N1; Fig. 1) for up to $1275 \mathrm{~d}$ (December 2005 to June 2010). Red snapper size range was 501 to $860 \mathrm{~mm}$ $\mathrm{TL}($ mean $\pm \mathrm{SD}=639 \pm 81 \mathrm{~mm}$; Table 1). Fish remained present at the sites until the end of the study, emigrated, died, or were removed by fishers, as determined by detections from the 5 receivers at each site and by fisher returns (Fig. 7). Individual fish were detected at sites from 1 to $1099 \mathrm{~d}$ (Table S1 in the supplement at www.int-res.com/ articles/suppl/m437p183.pdf). Within $6 \mathrm{~d}$ of release,

14 fish emigrated, 2 died and 1 was undetermined. After this initial postrelease effect $(<6 \mathrm{~d})$, it appeared that fish recovered and assumed normal movement behavior. Past this $6 \mathrm{~d}$ recovery period, the minimum residence time was $28 \mathrm{~d}$ (maximum = $1099 \mathrm{~d})$. The movements or deaths of these 17 fish (within $6 \mathrm{~d}$ of release) were assumed to be related to postrelease behaviors or mortality. Fish 31 showed this post-release emigration behavior. One day after release at Site A3, this fish was detected at 3 separate sites (A2 to A1 to A2), with an overall movement of $20 \mathrm{~km}$ in a $24 \mathrm{~h}$ period, then remained resident to A2 for 758 d (until hurricane Gustav). None of the other fish that left within $6 \mathrm{~d}$ of release were detected again or returned by fishers by the end of the study (10 June 2010). The fates of 6 fish were unknown, because their last detections occurred during periods when an outside receiver was not recording or removed during a hurricane. These fish were assumed to have emigrated based on data from other receivers at that site.

Residence time estimates derived from the K-M event analysis method varied slightly depending on the data set used in the analysis. The most appropriate estimate was calculated after the removal of the 17 fish leaving or dying immediately after tagging $(<6 \mathrm{~d})$, since this behavior appeared to be related to capture or 


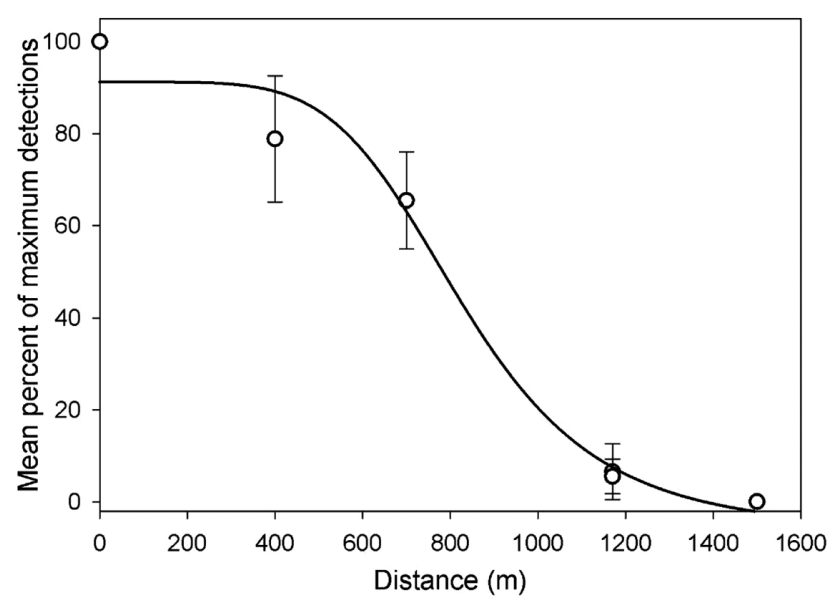

Fig. 6. Logistic relation of the mean percent of maximum expected detections of the control transmitter to VR2 distance $\left( \pm \mathrm{SD}_{i} \mathrm{R}^{2}=0.98\right)$. Sites $(\mathrm{A} 1, \mathrm{~A} 2, \mathrm{~A} 3$ and N1) were averaged from June 2006 to August 2008

tagging. Red snapper ( $\mathrm{n}=85$ fish) median residence time (when $50 \%$ of fish still present) was $542 \mathrm{~d}$ (406 to $661 \mathrm{~d}, 95 \%$ confidence limits [CL]). The annual site-fidelity estimate was $72 \% \mathrm{yr}^{-1}$ (Fig. 8). A logrank test of association did not detect a significant effect of fish size (TL) on residence time $(p=0.55)$. When fish with residence times $<6 \mathrm{~d}$ were included in the analysis ( $\mathrm{n}=102 \mathrm{fish})$, median residence time was reduced to $411 \mathrm{~d}$ ( 375 to $571 \mathrm{~d}, 95 \% \mathrm{CL}$ ); however, a log-rank test of homogeneity did not detect a significant difference between these $2 \mathrm{~K}-\mathrm{M}$ residence (survival) plots ( $p=0.08$; Fig. 8). The K-M plot derived from all 102 fish showed a steep initial slope, after which this slope showed the same pattern (slower rate of emigration) as the plot of fish with $>6 \mathrm{~d}$ residence. The site-fidelity estimate with all fish considered was $61 \% \mathrm{yr}^{-1}$ (Fig. 8).

\section{Storm effects on movement patterns}

Some fish ( $\mathrm{n}=19)$ showed movement patterns related to storms. Seven emigrations appeared to occur during or just after hurricanes Gustav (31 August 2008) and Ike (11 September 2008). During these 2 storms, wave heights in the study area were as high as $11 \mathrm{~m}$ and wind gusts were as high as $100 \mathrm{~km} \mathrm{~h}^{-1}$ (NOAA Buoy Station 42040, $102 \mathrm{~km}$ south of Mobile Bay), which reduced detection range and made it difficult to determine the fate of these fish. At least 1 fish died during these storms based on detections before and after storms (e.g. Fig. 3c). Before these storms 26 fish were present and immediately after the storms 18 fish remained.

One fish (No. 87) at Site N1 that was lost after these hurricanes, returned 2 mo later (24 October 2008) from the east, remained $1 \mathrm{mo}$, and then this fish and 3 others (Fish 74, 82, 86) emigrated to the east at the end of November 2008. Also, Fish 89 (A4) and Fish 94 (A5) emigrated in early December 2008 from deeper sites $(25 \mathrm{~m})$. These emigrations in November and December 2008 were during, or right after, several cold fronts passed over the area; however, 5 of these 6 fish returned to their respective sites as water temperatures increased $\left(>20^{\circ} \mathrm{C}\right)$ during several weeks in May and June 2009 (Fig. 9). Around the same time the following year, Fish 89 and 94 emigrated again, with Fish 94 returning again in May 2010. Fish 22 also showed movements associated with cold fronts and hurricanes. These movements were to another site $\sim 2 \mathrm{~km}$ E-SE of Site A1 (located during a survey). This large fish (815 mm TL) moved regularly to this alternate site, with winter spent at the release site and spring and summer spent at the alternative site over 2 yr. Another large ( $810 \mathrm{~mm}$ TL) red snapper (Fish 70) released at Site A3 on 29 November 2007

Table 1. Lutjanus campechanus. Summary of dates each study site was active (receivers deployed; start date, end date, time) and final status of fish released at each site (present, emigrated, caught, dead, unknown). Min.: minimum number of days a fish was present at the site; max.: maximum number of days a fish was present at the site after release; mean TL: mean $( \pm$ SD) total length of fish released at that site

\begin{tabular}{|c|c|c|c|c|c|c|c|c|c|c|c|c|}
\hline Site & Start date & End date & $\begin{array}{l}\text { Time } \\
\text { (d) }\end{array}$ & $\begin{array}{c}\text { Re- } \\
\text { leased }\end{array}$ & $\begin{array}{c}\text { Pres- } \\
\text { ent }\end{array}$ & $\begin{array}{l}\text { Emi- } \\
\text { grated }\end{array}$ & Caught & Dead & $\begin{array}{c}\text { Un- } \\
\text { known }\end{array}$ & $\begin{array}{l}\text { Min. } \\
\text { (d) }\end{array}$ & $\begin{array}{l}\operatorname{Max} . \\
\text { (d) }\end{array}$ & $\begin{array}{l}\text { Mean TL } \\
(\mathrm{mm})\end{array}$ \\
\hline A1 & 13 Dec 2005 & 10 Jun 2009 & 1275 & 26 & 1 & 8 & 14 & 3 & 0 & 1 & 1099 & $658 \pm 84$ \\
\hline A2 & 27 Jul 2006 & 23 Sep 2009 & 1154 & 19 & 4 & 7 & 4 & 3 & 1 & 1 & 856 & $689 \pm 75$ \\
\hline A3 & 9 Aug 2006 & 23 Sep 2009 & 1141 & 25 & 3 & 12 & 2 & 4 & 4 & 1 & 895 & $634 \pm 78$ \\
\hline A4 & 29 Aug 2007 & 13 Apr 2010 & 958 & 13 & 2 & 5 & 5 & 1 & 0 & 168 & 958 & $632 \pm 63$ \\
\hline A5 & 21 Oct 2008 & 8 Jun 2010 & 595 & 7 & 1 & 3 & 3 & 0 & 0 & 34 & 595 & $627 \pm 41$ \\
\hline N1 & 11 Dec 2007 & 29 Oct 2009 & 688 & 12 & 2 & 7 & 0 & 1 & 2 & 3 & 687 & $545 \pm 35$ \\
\hline All & 13 Dec 2005 & 8 Jun 2010 & 1638 & 102 & 13 & 42 & 28 & 12 & 7 & 1 & 1099 & $639 \pm 81$ \\
\hline
\end{tabular}



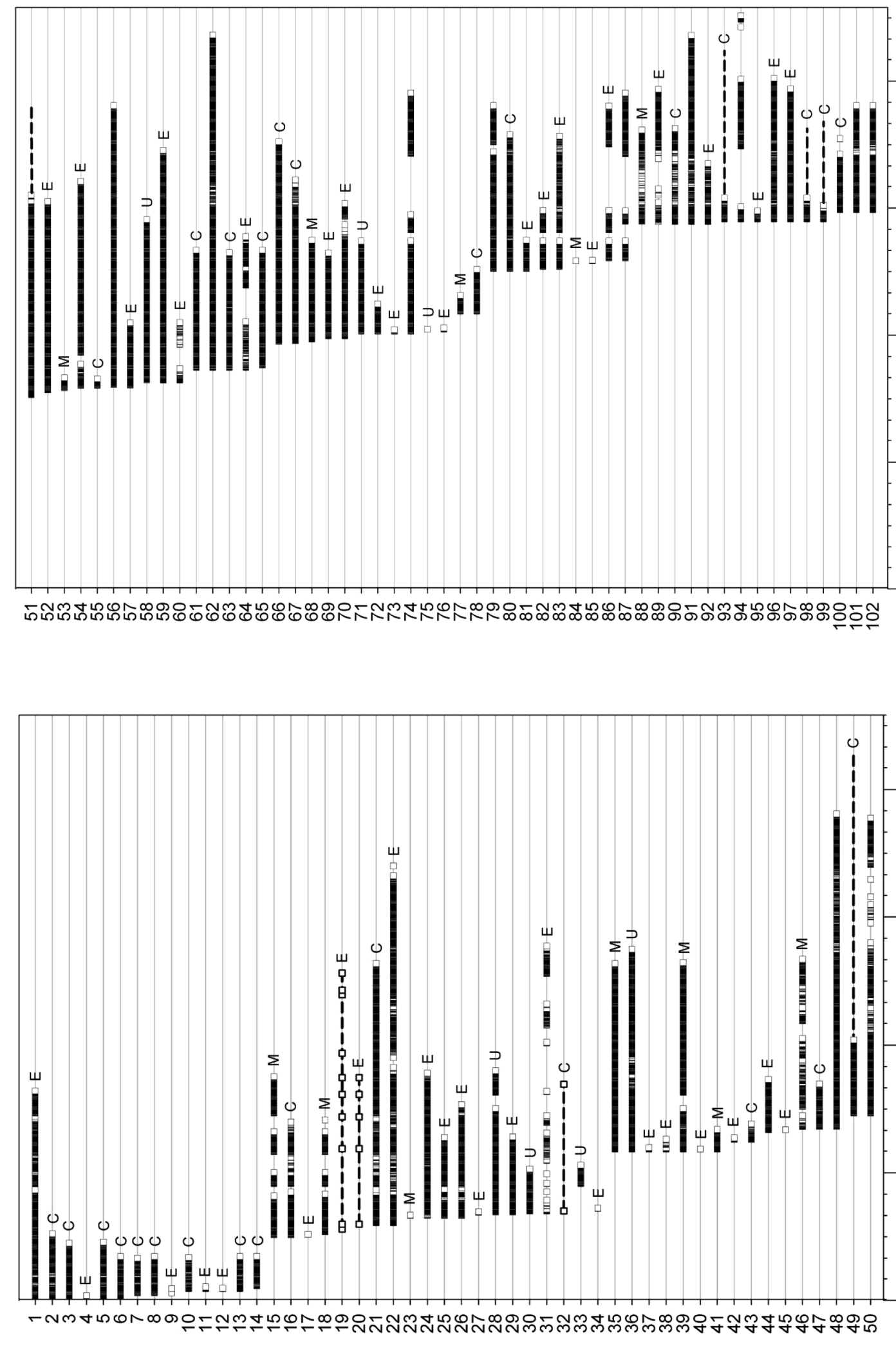

Fish number

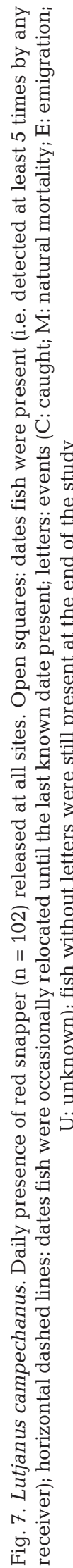




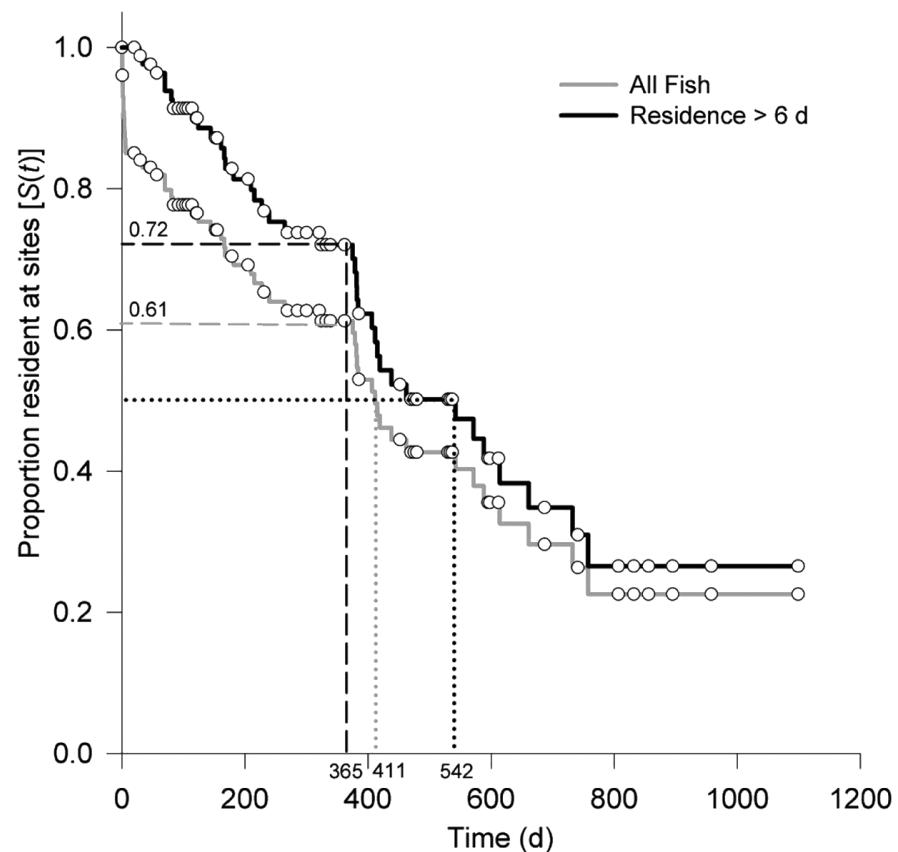

Fig. 8. Lutjanus campechanus. Kaplan-Meier survival (i.e. residence time) curves showing the proportion of red snapper remaining at study sites over time (d). Black line: fish remaining present longer than the $6 \mathrm{~d}$ post-release period $(\mathrm{n}=85)$; gray line: all fish released $(\mathrm{n}=102)$; dotted lines: median residence times ( $50 \%$ remaining); dashed lines: proportion of fish remaining at $365 \mathrm{~d}$ (site fidelity). Open circles show right-censor times of fish that were caught, died, or were still present at the end of the study

moved to Site A1 ( 6 km apart) on 2 separate occasions, staying at the alternate site for up to $21 \mathrm{~d}$ before returning to the release site. These directed movements all occurred as strong cold fronts passed over the study sites around 19 January, 25 January,
13 February and 6 March 2008. The movement time between study sites $(6 \mathrm{~km})$ was relatively short (1.3 to $4.8 \mathrm{~h}$ ) compared to the residence time of this fish at these sites (15 to $350 \mathrm{~d}$ ). Twelve fish moved to other locations, but returned to their release sites after long-term absences up to $7 \mathrm{mo}$, with some fish staying for the remainder of the study or again emigrating from the site.

The number of fish $(\mathrm{n}=38$ ) emigrating from the $12 \mathrm{~km}^{2}$ study sites in each season was compared to the null hypothesis of equal proportions of fish emigrating each season. There was a significant difference in the proportions (vs. equal) of fish emigrating in summer (37\%), winter (26\%), fall (29\%) and spring (8\%; likelihood-ratio: $\left.\chi^{2}=8.20, \mathrm{p}=0.04\right)$. There were also significant differences in the direction that fish emigrated from the release site, with $51 \%$ moving to the east, $26 \%$ to the south, $11 \%$ to the north and $11 \%$ to the west (likelihoodratio: $\chi^{2}=13.95, p=0.003$ ).

\section{Diel movement patterns}

Diel patterns of detections indicated that red snapper would move away from the reef sites at night. A time series of total detections per hour for 10 fish (released at Site A1) from 12 January 2006 to 31 March 2006 (just prior to capture of these fish) was obtained for FFT spectral analysis. The periodogram created from the spectral analysis had a strong peak at a period of $24.0 \mathrm{~h} \mathrm{cycle}^{-1}$ that indicated a daily sinusoidal cycle (Fig. 10a). These data were also analyzed with the LOESS procedure (local regression),

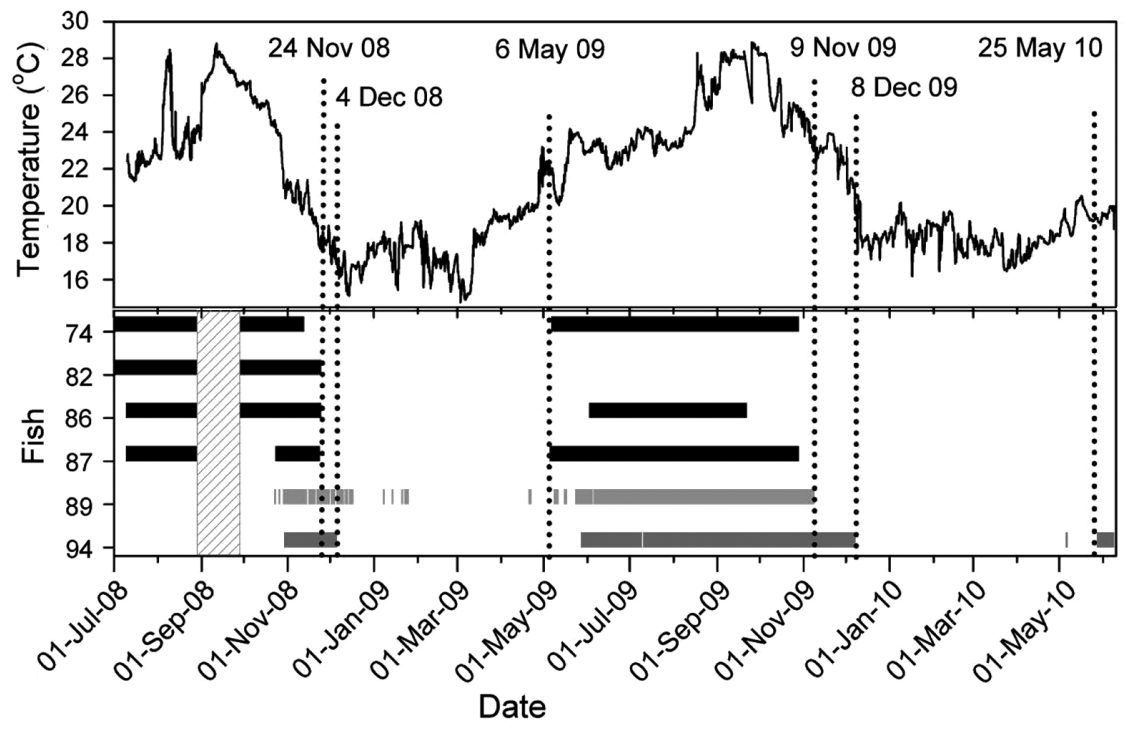

Fig. 9. Lutjanus campechanus. Daily detections of Fish 74, 82, 86 and 87 (Site N1, black), Fish 89 (A4, gray) and Fish 94 (A5, dark gray) at release sites represented by vertical dashes (bottom panel). Vertical dotted lines: cold fronts and storms when fish emigrated as water temperature decreased (top panel) and immigrated back to site as water temperature increased; hatched box: when receivers were removed due to hurricanes Gustav and Ike. Receivers were removed from Site N1 in October 2009, Site A4 in April 2010 and Site A5 in June 2010 

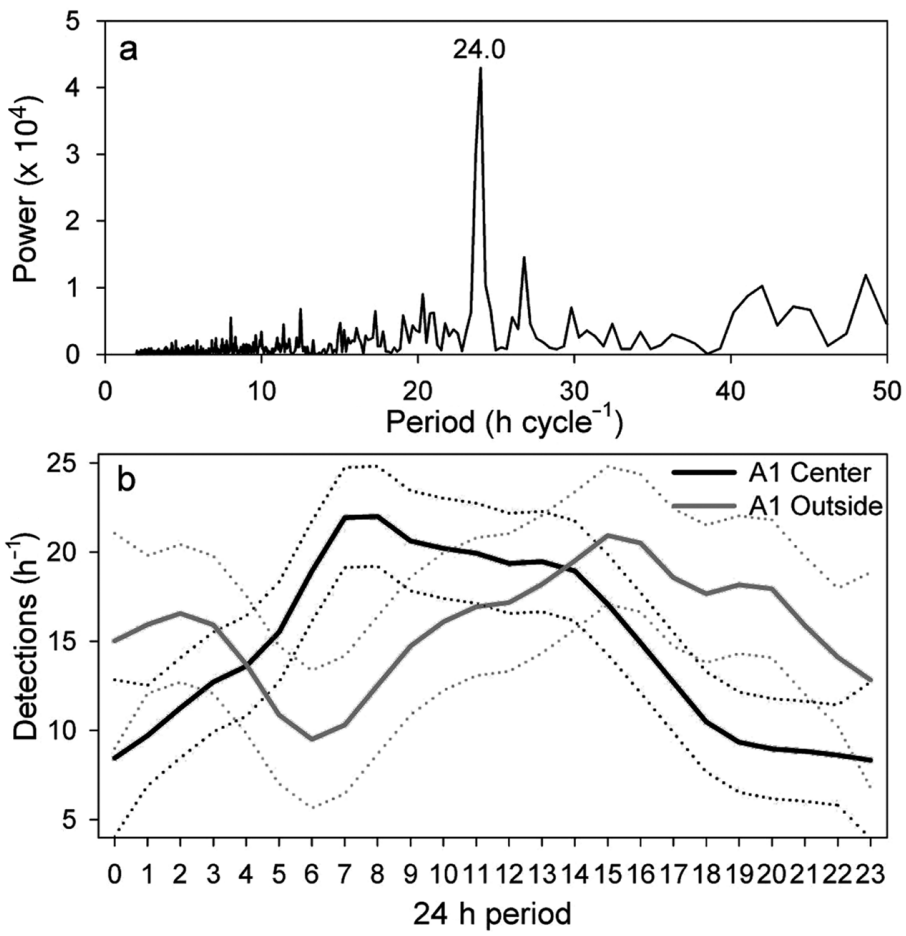

Fig. 10. Lutjanus campechanus. Time series of continuous receiver coverage $(\mathrm{n}=78 \mathrm{~d})$ for red snapper $(\mathrm{n}=10)$ at Site A1 from 12 January to 31 March 2006 analyzed by (a) spectral analysis (periodogram) of total detections per hour of these fish by the center receiver and (b) local regressions (LOESS) of detections per hour by the center (black line) and outside (gray line) receivers. The periodogram shows a strong peak at a period of $24 \mathrm{~h}$ indicating a diel cycle in detection frequencies. The LOESS showed high detections when fish were close to the reef, and lower detections when fish were further from the reef. Dotted lines: $95 \%$ confidence limits day, with a maximum at 15:00 h and remaining relatively high throughout the night (Fig. 10b). Based on detection range data (Fig. 6; detections decreased with increase in transmitter distance), fish showing these patterns (69\%) were in close proximity to the reef at sunrise and gradually moved further from reefs toward the end of the day and at night, again remaining close to the reef around sunrise (e.g. Fig. 10b).

Not all fish at all sites showed movement away from the structure at night, and fish that did move away from the structure at night did not do so every night. For example, Fish 21 moved toward the west, $\sim 1 \mathrm{~km}$ away from the structure, during both night and day (Fig. 11). These movements from 1 to 17 July 2008 were significantly correlated with tidal stage. Although tidal effects were correlated with diel effects $(r=0.41, p<0.0001)$, the influence of both tide and diel periods on detections per hour of Fish 21 by the west receiver were detected with a stepwise regression. Over this 18 d period, detections on 12 d were significantly affected by diel period $\left(\mathrm{r}^{2}\right.$ range: 0.09 to 0.65, $\mathrm{p}<0.02$ ) and detections on $7 \mathrm{~d}$ were significantly affected by tidal cycles $\left(\mathrm{r}^{2}\right.$ range: 0.19 to $0.72, \mathrm{p}<0.006$ ). All r-values (correlation coefficients) were negative, indicating Fish 21 tended to move toward the west during low tides and at lower light levels (e.g. Fig. 11). with an estimate of total detections per hour from each $1 \mathrm{~h}$ period of each day $(\mathrm{n}=78 \mathrm{~d})$. Detections at the center receiver (near the structure) were greater during daylight hours $(07: 00$ to $15: 00 \mathrm{~h})$, with a peak in detections at 07:00 $\mathrm{h}$ (around sunrise for this time of year). Pooled detections at the outside receivers (1.1 km away) were lowest at sunrise $(07: 00 \mathrm{~h})$ and tended to increase throughout the

Fig. 11. Lutjanus campechanus. Total detections each hour of Fish 21 by the center (solid black line) and the west (dotted black line) receivers at Site A1 from 1 to 17 July 2008. Shaded bars show nighttime periods. Tidal cycle (solid gray line) is plotted in upper panel

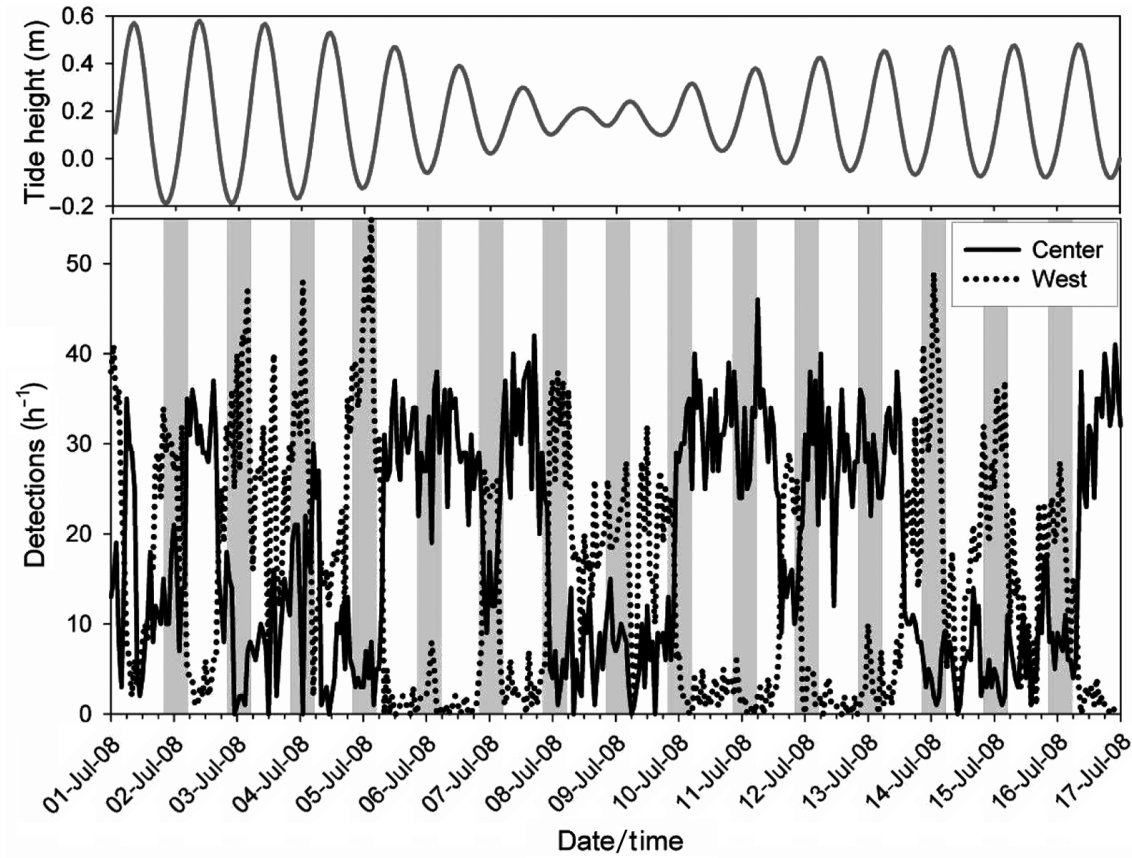




\section{DISCUSSION}

The residence, site fidelity and movement patterns of red snapper Lutjanus campechanus around various structured habitats off Alabama were successfully estimated with long-term telemetry, and the design of the receiver arrays enabled fishery-independent estimations of emigration, fishing and natural mortalities in an open water system. To date, this was the longest telemetry study for red snapper (twice as long), which contributed to the highest residence time and site-fidelity estimates obtained for this species for any habitat, with many fish resident for over a year $(n=37)$ and some for as long as $2 \mathrm{yr}(\mathrm{n}=9)$. The high estimates of median residence time (542 d) and site fidelity ( $72 \%$ ) were also due to being able to account for natural mortality, fishing mortality and post-release behaviors. Large red snapper (>500 mm TL) permitted the use of longlife transmitters (4 to 6 yr) that had detection ranges of up to $1600 \mathrm{~m}$. The use of these transmitters may account for the longer residence time and higher fidelity estimates compared to studies with smaller red snapper $(<500 \mathrm{~mm})$ and shorter lived, weaker signal strength transmitters (Peabody 2004, McDonough 2009). Also, unique to this study was the use of stationary control transmitters that allowed control of changing transmitter detection rates due to changing environmental parameters and more accurate estimation of mortality, movement patterns and residence.

\section{Detection rate and range validation}

Residence studies typically release multiple fish at one location, but few account for changes in detection rate related to different numbers of ultrasonically tagged fish present (Simpfendorfer et al. 2008). Multiple Vemco Rcode transmitters within the detection range of a receiver significantly affected detection rate of individual transmitters due to signal collisions of transmitters with the same frequency $(69 \mathrm{kHz})$. Significant changes in detections of the stationary control transmitter occurred as fish emigrated or were added to a site. If ignored, these detection changes of remaining fish would be interpreted as seasonal movement patterns.

Telemetry studies should consider detection range changes when determining seasonal movements from detection rate (e.g. Arendt et al. 2001, Starr et al. 2002, Szedlmayer \& Schroepfer 2005, Topping et al. 2006, Meyer et al. 2007). A number of studies have tested the detection range of the transmitters used in fish, but these tests are typically short term, used only to determine telemetry array set-ups (e.g. Arendt et al. 2001, Simpfendorfer et al. 2002, Finstad et al. 2005, Giacalone et al. 2005, Szedlmayer \& Schroepfer 2005, Heupel et al. 2006, Hedger et al. 2008). If detection range is not measured throughout the study, there can be unknown gaps in detection within the array that allow fish to pass through undetected, and a reduced detection range (loss of detection) could be interpreted as fish leaving the study. The mean detection rate (mean proportion of expected detections), determined as distances increased from the control transmitter in the present study, was similar to detection range estimates from Szedlmayer \& Schroepfer (2005). Both the present study and that of Szedlmayer \& Schroepfer (2005) had a detection rate as high as $100 \%$ at $600 \mathrm{~m}$, a steep drop to $50 \%$ at $800 \mathrm{~m}$ and a maximum detection distance of $1600 \mathrm{~m}$. Since detection range was frequently $>1 \mathrm{~km}$, fish were consistently detected by outside receivers when still present at the release site, but at a reduced rate compared to the detections at the center. The mean detection range significantly varied over the study, and being able to account for this variability allowed for better interpretation of fish detection data.

\section{Residence time and site fidelity}

Telemetry studies of red snapper and other species have detected an initial post-release emigration behavior that is likely related to the capture and handling stress associated with tagging procedures (Gurshin \& Szedlmayer 2004, Peabody 2004, Schroepfer \& Szedlmayer 2006, Lowe et al. 2009, McDonough 2009). Initial high declines (emigration plus mortality in the present study) are typically referred to as the 'bathtub effect' in post-surgery survival studies, and survival (i.e. emigration) rates quickly 'level off' after this initial loss (Gavrilov \& Gavrilova 1991). In the present study, 17 of the 102 $(17 \%)$ released fish emigrated or died within the first $6 \mathrm{~d}$. These fish were never detected again and were not reported as captured by fishers. Schroepfer \& Szedlmayer (2006) 'lost' 12 of 77 (16\%) red snapper within $3 \mathrm{~d}$, and they considered this initial loss of fish a tagging artifact. Peabody (2004) released 125 red snapper, but $28(22 \%)$ of these fish were never detected or reported caught by fishers. McDonough (2009) released fish $(n=36)$ at the same oil platforms ('the Circle') and at least $53 \%$ left the site (or were 
not detected) over the $14 \mathrm{~d}$ study. Similar 'loss' patterns $(30 \%$ loss in the first $6 \mathrm{~d}$ ) were shown by various ultrasonically tagged fish species on oil platforms off California (Lowe et al. 2009). These early emigrations were most likely due to capture and tagging stress, and, after some initial recovery period, the remaining fish showed a significantly lower emigration rate.

Since traditional mark-recapture studies cannot constantly monitor the presence or absence of tagged fish at study sites, it is uncertain if red snapper in these previous studies showed the same initial postrelease behavior (and mortality). If all tagging methods cause this behavior in red snapper, then previous estimates of site fidelity and residence time based on mark-recapture may be underestimated because conventional tagging cannot account for this effect (Szedlmayer \& Shipp 1994, Patterson et al. 2001, Patterson \& Cowan 2003, Diamond et al. 2007, Strelcheck et al. 2007). Patterson \& Cowan (2003) calculated red snapper site fidelity $\left(\mathrm{SF}=\mathrm{e}^{-Q} ; Q=\right.$ instantaneous emigration rate) of approximately $25 \% \mathrm{yr}^{-1}$, with an instantaneous rate of decline of recaptures of $D=1.47 \mathrm{yr}^{-1}$ for fish at their site, assuming no fishing mortality $(F)$, where $Q=D$ - instantaneous total mortality $(Z=0.09)$. Strelcheck et al. (2007) estimated an overall SF of $51.5 \% \mathrm{yr}^{-1}$ from a $D$ of $0.72 \mathrm{yr}^{-1}$, assuming a $Z$ or $M$ of 0.10 (natural mortality, i.e. no fishing). Substantial differences among the present study and these 2 previous studies were the abilities of the present study to account for fishing mortality, natural mortality, emigration and the initial stress response. In addition, these previous studies assumed no tag shedding and that all recaptured tagged fish were correctly recognized. Accounting for these factors could easily be responsible for the higher site fidelity $\left(72 \% \mathrm{yr}^{-1}\right)$ observed in the present study.

Another factor that may have attributed to differences in site-fidelity estimates between the present and previous studies was differences in tagged fish size. Since red snapper maturity $(100 \%, 440 \mathrm{~mm}$ FL [forklength]; $50 \%, 275 \mathrm{~mm}$ FL) occurs at sizes smaller than those used in the present study (>500 mm TL), differences between these studies may be due to an ontogenetic change in movement patterns (Render 1995, Jackson et al. 2007). Three main hypotheses of size effects on movements have been suggested: (1) larger fish may move more since their size may make them less susceptible to predation, (2) smaller fish may move more or show less fidelity due to competitive exclusion from preferred habitat by larger conspecifics, and (3) larger fish may need to move over a larger area to acquire the prey required to meet their energetic needs (Wakeman et al. 1979, Szedlmayer \& Schroepfer 2005, Strelcheck et al. 2007, Gallaway et al. 2009, Topping 2009, Mudrak \& Szedlmayer in press). The present study had the largest mean fish sizes for any red snapper tagging study (mean: $639 \mathrm{~mm}$ ), and fish size did not affect residence time for the size range monitored (501 to $860 \mathrm{~mm} \mathrm{TL}$ ). Szedlmayer \& Schroepfer (2005) were unable to correlate residence time to fish size, but did find that larger red snapper spent less time within receiver range. This movement pattern was also evident in a study that manually tracked large red snapper (>500 $\mathrm{mm} \mathrm{TL}$ ) at Sites A4 and A5 over $24 \mathrm{~h}$ periods, and found larger fish moved a greater mean distance from the reef than smaller fish (Topping 2009). In contrast, Peabody (2004) used telemetry methods for smaller red snapper on oil rigs, and estimated shorter residence times than those found in the present study; however, this difference in residence may have also been affected by habitat, transmitter life ( 200 vs. 2000 d nominal battery life) and a distinct thermocline, rather than fish size. Patterson et al. (2001) found that red snapper movements away from tagging sites increased with fish size, and Diamond et al. (2007) also showed a fish size effect whereby larger red snapper had a greater probability of movement. However, in general, Patterson et al. (2001) and Diamond et al. (2007) tagged much smaller fish on average (Patterson et al. 2001, $335 \mathrm{~mm}$ TL; Diamond et al. 2007, $363 \mathrm{~mm}$ TL) than those tagged in the present study.

The spatial scales on which site fidelity has been estimated were inconsistent among past studies and may affect what constitutes the high site fidelity of red snapper (Schroepfer \& Szedlmayer 2006, Strelcheck et al. 2007). McDonough (2009) suggested that a better approach for estimating site fidelity would be in the context of a fish's home range (rather than the detection range of the transmitters used). However, definitions of home range can also vary from daily activity spaces to seasonal area use, and measurements of home range tend to increase with temporal scale (Zeller 1997, Heupel et al. 2004, Topping et al. 2005, 2006). Strelcheck et al. (2007) suggested that since red snapper can live up to $50 \mathrm{yr}$ (Wilson \& Nieland 2001), they show relatively low site fidelity to small artificial reefs $(0.1 \%$ of fish remaining after $10 \mathrm{yr}$ ). As shown in the present study, red snapper will stay at an artificial site for extended periods then quickly move over open sand-mud habitat to another artificial site for extended periods. If only the first site is considered it might be concluded that red snapper 
showed low site fidelity to artificial reefs, but high habitat fidelity is apparent when accounting for quick movements followed by long-term residency to a second artificial reef. Thus, the demonstration of residence to a single structure may not be as important as the overall high use of these types of habitats. The general residence in areas that are subjected to more intense fishing pressure, such as the Hugh Swingle General Permit Area, has been suggested by Strelcheck et al. (2007) to be detrimental to red snapper. However, there are a high number $(>1000)$ of artificial structures in this area with a range of fishing mortalities (Topping 2009), and many of these structures were privately deployed with unpublished locations or have been relocated to unknown locations by hurricanes (Minton \& Heath 1998, Turpin \& Bortone 2002, Larsen 2005). These 'private' unpublished structures may provide benefits to red snapper that offset any higher fishing mortality at 'public' (published) reefs (Turpin \& Bortone 2002, Larsen 2005).

\section{Long-term movement patterns}

The present study is the first to show red snapper returning to their original release site after emigrating distances as far as $8 \mathrm{~km}$ and being absent for as long as $7 \mathrm{mo}$. The directed movements (e.g. $8 \mathrm{~km}$ in $1.6 \mathrm{~h}$ ) of some red snapper in the present study to other structured habitats indicate possible previous knowledge of these alternate sites. For example, Fish 70 emigrated from its original site (A3) to another site (A1) and then returned to A3. Also, over 2 consecutive years, Fish 22 would also move to another structure $\sim 2 \mathrm{~km}$ to the east in spring and return to the release site in fall. The movements to and from different habitat structures may provide benefits that make up for the expenditure of energy associated with excursions (Wakeman et al. 1979). Consistent with this idea of ecological benefit for 'movers,' Diamond et al. (2007) showed higher growth rates for movers compared to 'stayers.'

Movement of other fish species to and from particular habitats appears important, as indicated from homing studies, and movement is probably due to prey availability, shelter and spawning opportunities, with different artificial reefs providing differing levels of these resources (Matthews 1990, Mitamura et al. 2005, Lowe et al. 2009). Homing of red snapper has not been verified in other tagging studies that have translocated this species to other habitats, but these fish did tend to leave the release site at a higher rate than non-translocated fish (Patterson et al. 2001, Watterson et al. 1998, Peabody 2004).

Storms (e.g. cold fronts and hurricanes) appeared to initiate movement of red snapper in the present study. For example, the shallowest sites (N1, A4, A5) might be more affected by cold fronts compared to deeper sites. In November and December 2008, 6 fish emigrated from these sites towards the east right before or after several cold fronts, and when water temperatures warmed up in May and June 2009, 5 of these fish returned from an unknown location ( $>2 \mathrm{~km}$ away). Sites A4 and A5 are slightly deeper $(25 \mathrm{~m})$ than Site N1 $(20 \mathrm{~m})$, and the emigration of fish at the deeper sites was delayed $\sim 10 \mathrm{~d}$ (water temperature cooled earlier at N1). It is possible that these fish were avoiding wave action and cold water masses by moving to deeper sites as suggested by Moseley (1966). Overall, 19 fish had movements that appeared related to storms, with some fish leaving the study site just prior (hours to $1 \mathrm{~d})$ to the storm passing over the site. Heupel et al. (2003) found that blacktip sharks Carcharhinus limbatus may sense barometric pressure changes, as the sharks would leave the shallow bay to deeper water just prior to the arrival of a tropical storm. The present study also indicates that some fish may detect the pressure changes (decrease) associated with storm fronts and hurricanes.

Overall, 7 fish were lost during hurricanes Gustav and Ike, but most fish (73\%) remained at study sites, despite waves to $11 \mathrm{~m}$ and winds up to $100 \mathrm{~km} \mathrm{~h}^{-1}$. Mark-recapture studies have detected greater dispersal of red snapper from recaptures after hurricanes (Watterson et al. 1998, Patterson et al. 2001). In contrast, the present study was similar to other telemetry studies that showed most red snapper remained resident to reef structures through major hurricanes (Peabody 2004, Szedlmayer \& Schroepfer 2005). Differences in hurricane-related dispersal between studies may be due to differences in reef type and size, with fish remaining on larger, stable structures (Watterson et al. 1998, Patterson et al. 2001, Peabody 2004, Szedlmayer \& Schroepfer 2005). The present study did find a greater proportion of these emigrations of red snapper were toward the east $(51 \%)$. Other studies of red snapper in the northern GOM have also detected this eastward component to recaptures or relocations (Beaumariage 1969, Watterson et al. 1998, Patterson et al. 2001, Peabody 2004). Other studies have attributed these eastward displacements to hurricanes, or to higher fishing pressure to the east, which would produce a similar result even if fish randomly dispersed in various 
directions from the study site (Patterson et al. 2001). The eastern emigration pattern of some fish in the present study provides evidence that higher fishing pressure to the east is not the only factor contributing to the apparent eastward redistribution of red snapper.

\section{Diel movements}

Diel movement patterns were detected for red snapper in the present study, and patterns were similar to diel movements described from previous telemetry studies of red snapper and other lutjanids (Peabody 2004, Lindholm et al. 2005, Szedlmayer \& Schroepfer 2005, Meyer et al. 2007, McDonough 2009, Topping 2009). Detection patterns showed diel movements for fish over all seasons; however, some fish only showed diel patterns during specific seasons (e.g. Fish 21; Fig. 11) and patterns were not always consistent each day. When patterns were detected, most fish $(69 \%)$ moved away from the structure late in the day or at sunset and returned sometime before sunrise. Both Peabody (2004) and Szedlmayer \& Schroepfer (2005) indicated red snapper moved away from the reef at night from a decrease in detections of fish by a central receiver. Other telemetry studies have also shown detections decreased at night, but these patterns were attributed to movement into structure rather than movement away from structure (Arendt et al. 2001, Giacalone et al. 2005, Topping et al. 2006). In the present study, detections also increased at surrounding receivers when detections decreased at the center receiver; thus, movement away from structure was validated, which supports the results of Peabody (2004) and Szedlmayer \& Schroepfer (2005). Szedlmayer \& Schroepfer (2005) used transmitters comparable to those in our study, and found some fish $(n=4)$ showed diel patterns, with varied results between day and night detections. The diel movements for large red snapper in the present study were relatively consistent with patterns for smaller red snapper monitored by Peabody (2004) at oil platforms. In contrast, McDonough (2009) found red snapper were significantly further from the same platforms during the day than at night during a short-term telemetry study (14 d) in late spring and early summer. These spatial and temporal differences in diel movement patterns in these telemetry studies may indicate that habitat use (reef vs. sand) may vary with season and location, and may be due to seasonal or daily changes in diets (Ouzts
\& Szedlmayer 2003, McCawley \& Cowan 2007). Variability in the presence of reef and sand organisms during both day and night, and over seasons, may result in differences in diel movements that simply reflect food availability near the structure over diel and seasonal cycles (Ouzts \& Szedlmayer 2003, McCawley \& Cowan 2007). Intra-specific variability in movement patterns of fishes appears prevalent, and it will be necessary to continue to determine the causal factors (e.g. habitat, food availability, season, etc.) associated with this variability to better manage this species and others (Tolimieri et al. 2009).

In summary, this 4.5 yr study showed long-term residence of red snapper at both artificial and natural habitats in the northern GOM. The design of the receiver arrays deployed at each site and the type of transmitter (long term and long range) used enabled continuous monitoring of fish within a relatively large area $\left(12 \mathrm{~km}^{2}\right.$ at each site). The addition of a control transmitter to the design of this telemetry array allowed for the estimation of changes in detection range throughout the study. These telemetry methods provided estimates of residence that took into account natural mortality, fishing mortality and post-release behaviors. The consideration of these factors and length of our study have contributed to high site-fidelity rates $\left(72 \% \mathrm{yr}^{-1}\right)$ and longer residence times (median: 542 d, range: 20 to 1099 d) of red snapper to artificial and natural habitat types than previously reported in other tagging studies. An important fact to point out is that the fish tagged at each site were present for some undetermined amount of time prior to their initial capture at that structure, as is true in other tagging studies. Thus, residence time and fidelity are underestimated in all tagging studies. Though fidelity of most fish to the original release location was high, some fish did move around the release site, and others emigrated to other sites. This is the first study to detect directed movements to and from artificial habitat sites as far as $8 \mathrm{~km}$. Movements may occur for various reasons; seasons, cold fronts and hurricanes appeared to affect the timing of red snapper emigration (and immigration) in the present study. Diel movements are probably related to foraging behavior as indicated by some diel diet shifts shown in previous studies (Ouzts \& Szedlmayer 2003), but these movements were not consistent among different fish or seasons. These movement patterns showed red snapper had a strong association with these artificial habitats, and this implies that these artificial reefs provide suitable habitat for these fish. 
Acknowledgements. We thank S. Beyer, D. Miller, P. Mudrak, C. Simmons and T. Syc for field assistance. We thank L. Swann and Y. Brady for reviewing earlier versions of this manuscript. This project was funded by the National Oceanic and Atmospheric Administration, National Fisheries Service MARFIN program Award Number NA06 NMF4330054 and Marine Resources Division, Alabama Department of Conservation and Natural Resources. This study is a contribution of the Alabama Agricultural Experiment Station and Department of Fisheries and Allied Aquacultures, Auburn University.

\section{LITERATURE CITED}

Allison PD (1995) Survival analysis using the SAS ${ }^{\circledR}$ system: a practical guide. SAS Institute, Cary, NC

Arendt MD, Lucy JA, Evans DA (2001) Diel and seasonal activity patterns of adult tautog, Tautoga onitis, in lower Chesapeake Bay, inferred from ultrasonic telemetry. Environ Biol Fish 62:379-391

Beaumariage DS (1969) Returns from the 1965 Schlitz tagging program including a cumulative analysis of previous results. Fla Dep Nat Resour Mar Res Lab Tech Ser 59: $1-38$

Bohnsack JA (1989) Are high densities of fishes at artificial reefs the result of habitat limitation or behavioral preference? Bull Mar Sci 44:631-645

Bradley E, Bryan CE (1975) Life history and fishery of the red snapper (Lutjanus campechanus) in the northwestern Gulf of Mexico. Proc Gulf Caribb Fish Inst 27:77-106

Camber CI (1955) A survey of the red snapper fishery of the Gulf of Mexico, with special reference to the Campeche Banks. Fla Board Conserv Mar Res Lab Tech Ser 12:1-64

Chambers RC, Leggett WC (1989) Event analysis applied to timing in marine fish ontogeny. Can J Fish Aquat Sci 46: 1633-1641

Cleveland WS (1979) Robust locally weighted regression and smoothing scatterplots. J Am Stat Assoc 74:829-836

Cleveland WS, Devlin SJ (1988) Locally weighted regression: an approach to regression analysis by local fitting. J Am Stat Assoc 83:596-610

Cody RP, Smith JK (2006) Applied statistics and the SAS programing language, 5th edn. Prentice Hall, Upper Saddle River, NJ

Cohen RA (1999) An introduction to PROC LOESS for local regression. In: Proc 24th Annu SAS ${ }^{\circledR}$ Users Group Int Conf. Paper 273, SAS Institute, Cary, NC, p 1584-1592

Cox DR, Oakes D (1984) Analysis of survival data. Chapman and Hall, New York, NY

Diamond SL, Campbell MD, Olson D, Wang Y, Zeplin J, Qualia S (2007) Movers and stayers: individual variability in site fidelity and movements of red snapper off Texas. In: Patterson WF III, Cowan JH Jr, Fitzhugh GR, Nieland DL (eds) Red snapper ecology and fisheries in the U.S. Gulf of Mexico. Am Fish Soc Symp 60:163-187

Dufrene TA (2005) Geological variability and Holocene sedimentary record on the northern Gulf of Mexico inner to mid-continental shelf. Master's thesis, Louisiana State University, Baton Rouge, LA

Fable Jr WA (1980) Tagging studies of red snapper (Lutjanus campechanus) and vermilion snapper (Rhomboplites aurorubens) off the South Texas coast. Contrib Mar Sci 23:115-121

Finstad B, Okland F, Thorstad EB, Bjorn PA, McKinley RS (2005) Migration of hatchery-reared Atlantic salmon and wild anadromous brown trout post-smolts in a Norwegian fjord system. J Fish Biol 66:86-96

Gallaway BJ, Szedlmayer ST, Gazey WJ (2009) A life history review for red snapper in the Gulf of Mexico with an evaluation of the importance of offshore petroleum platforms and other artificial reefs. Rev Fish Sci 17:48-67

Gavrilov LA, Gavrilova NS (1991) The biology of life span: a quantitative approach. Harwood Academic Publishers, Chur

Giacalone VM, D'Anna G, Garofalo G, Collins K, Badalamenti $F$ (2005) Estimation of positioning error from an array of automated omnidirectional receivers in an artificial reef area. In: Spedicato MT, Lembo G, Marmulla G (eds) Aquatic telemetry: advances and applications. Proc 5th Conf Fish Telemetry. FAO/COISPA, Rome, p 245-253

Gitschlag GR, Schirripa MJ, Powers JE (2003) Impacts of red snapper mortality associated with the explosive removal of oil and gas structures on stock assessments of red snapper in the Gulf of Mexico. In: Stanley DR, Scarborough-Bull A (eds) Fisheries, reefs, and offshore development. Am Fish Soc Symp 36:83-94

$>$ Green AW, Matlock GC, Weaver JE (1983) A method for directly estimating the tag-reporting rate of anglers. Trans Am Fish Soc 112:412-415

Gurshin CWD, Szedlmayer ST (2004) Short-term survival and movements of Atlantic sharpnose sharks captured by hook-and-line in the north-east Gulf of Mexico. J Fish Biol 65:973-986

> Hedger RD, Martin F, Dodson J, Hatin D, Caron F, Whoriskey FG (2008) The optimized interpolation of fish positions and speeds in an array of fixed acoustic receivers. ICES J Mar Sci 65:1248-1259

Heupel MR, Simpfendorfer CA, Hueter RE (2003) Running before the storm: blacktip sharks respond to falling barometric pressure associated with Tropical Storm Gabrielle. J Fish Biol 63:1357-1363

> Heupel MR, Simpfendorfer CA, Hueter RE (2004) Estimation of shark home ranges using passive monitoring techniques. Environ Biol Fishes 71:135-142

- Heupel MR, Semmens JM, Hobday AJ (2006) Automated acoustic tracking of aquatic animals: scales, design and deployment of listening station arrays. Mar Freshw Res 57:1-13

Heupel MR, Reiss KL, Yeiser BG, Simpfendorfer CA (2008) Effects of biofouling on performance of moored data logging acoustic receivers. Limnol Oceanogr Methods 6: 327-335

Jackson MK, Cowan JH Jr, Neiland DL (2007) Demographic difference in northern Gulf of Mexico red snapper reproduction maturation: implication for the unit stock hypothesis. In: Patterson III WF, Cowan Jr JH, Fitzhugh GR, Nieland DL (eds) Red snapper ecology and fisheries in the U.S. Gulf of Mexico. Am Fish Soc Symp 60:217-227

Kalbfleisch JD, Prentice RL (1980) The statistical analysis of failure time data. John Wiley \& Sons, New York, NY

Kaplan EL, Meier P (1958) Nonparametric estimation from incomplete observations. J Am Stat Assoc 53:457-481

Klein JP, Moeschberger ML (1997) Survival analysis: techniques for censored and truncated data. Springer-Verlag, New York, NY

Larsen SJ (2005) Influence of high-resolution spatial information on resource exploitation: an example from angler impacts on artificial reefs. Master's thesis, University of Florida, Gainesville, FL 
Lindholm J, Kaufman L, Miller S, Wagschal A, Newville M (2005) Movement of yellowtail snapper (Ocyurus chrysurus Block, 1790) and black grouper (Mycteroperca bonaci Poey, 1860) in the northern Florida Keys national marine sanctuary as determined by acoustic telemetry. Marine sanctuaries conservation series MSD-05-4, US Department of Commerce, National Oceanic and Atmospheric Administration, Marine Sanctuaries Division, Silver Spring, MD

Lingo ME, Szedlmayer ST (2006) The influence of habitat complexity on reef fish communities in the northeastern Gulf of Mexico. Environ Biol Fishes 76:71-80

> Lowe CG, Anthony KM, Jarvis ET, Bellquist LF, Love MS (2009) Site fidelity and movement patterns of groundfish associated with offshore petroleum platforms in the Santa Barbara Channel. Mar Coast Fish Dyn Mgmt Ecosys Sci 1:71-89

- Matthews KR (1990) An experimental study of the habitat preferences and movement patters of copper, quillback, and brown rockfishes (Sebastes spp.). Environ Biol Fishes 29:161-178

McCawley JR, Cowan JH Jr (2007) Seasonal and size specific diet and prey demand of red snapper on Alabama artificial reefs. In: Patterson WF III, Cowan JH Jr, Fitzhugh GR, Nieland DL (eds) Red snapper ecology and fisheries in the U.S. Gulf of Mexico. Am Fish Soc Symp 60:77-104

McDonough M (2009) Oil platforms and red snapper movement and behavior. Master's thesis, Louisiana State University, Baton Rouge, LA

Meyer CG, Papastamatiou YP, Holland KN (2007) Seasonal, diel, and tidal movements of green jobfish (Aprion virescens, Lutjanidae) at remote Hawaiian atolls: implications for marine protected area design. Mar Biol 151:2133-2143

Minton RV, Heath SR (1998) Alabama's artificial reef program: building an oases in the desert. Gulf Mex Sci 16: 105-106

> Mitamura H, Arai N, Sakamoto W, Mitsunaga Y and others (2005) Role of olfaction and vision in homing behaviour of black rockfish Sebastes inermis. J Exp Mar Biol Ecol 322:123-134

Moe MA (1963) A survey of offshore fishing in Florida. Fla Board Conserv Mar Lab Prof Pap Ser 4

Moseley FN (1966) Biology of the red snapper, Lutjanus aya Block, of the northwestern Gulf of Mexico. Publ Inst Mar Sci Univ Tex 11:90-101

Mudrak PA, Szedlmayer ST (in press) Predation and competition effects on age-0 red snapper on artificial reefs in the northern Gulf of Mexico. Trans Am Fish Soc

> Ohta I, Kakuma S (2004) Periodic behavior and residence time of yellowfin and bigeye tuna associated with fish aggregating devices around Okinawa Islands, as identified with automated listening stations. Mar Biol 146: 581-594

Ouzts AC, Szedlmayer ST (2003) Diel feeding patterns of red snapper on artificial reefs in the north-central Gulf of Mexico. Trans Am Fish Soc 132:1186-1193

Parker RO Jr, Colby DR, Willis TD (1983) Estimated amount of reef habitat on a portion of the U.S. South Atlantic and Gulf of Mexico continental shelf. Bull Mar Sci 33: 935-940

Patterson WF III, Cowan JH Jr (2003) Site fidelity and dispersion of red snapper associated with artificial reefs in the northern Gulf of Mexico. In: Stanley DR, Scarborough-Bull A (eds) Fisheries, reefs, and offshore develop- ment. Am Fish Soc Symp 36:189-194

Patterson WF III, Watterson JC, Shipp RL, Cowan JH Jr (2001) Movement of tagged red snapper in the northern Gulf of Mexico. Trans Am Fish Soc 130:533-545

Peabody MB (2004) The fidelity of red snapper (Lutjanus campechanus) to petroleum platforms and artificial reefs in the northern Gulf Of Mexico. Master's thesis, Louisiana State University, Baton Rouge, LA

> Pollock KH, Winterstein SR, Bunck CM, Curtis PD (1989) Survival analysis in telemetry studies: the staggered entry design. J Wildl Manag 53:7-15

Render JH (1995) The life history (age, growth, and reproduction) of red snapper (Lutjanus campechanus) and its affinity for oil and gas platforms. Doctoral dissertation, Louisiana State University, Baton Rouge, LA

Schirripa MJ, Legault CM (1999) Status of the red snapper in U.S. waters of the Gulf of Mexico: updated through 1998. SFD-99/00-75, Southeast Fisheries Science Center, Miami Laboratory, NMFS, Miami, FL

Schroeder WW, Shultz AW, Dindo JJ (1988) Inner-shelf hardbottom areas, northeastern Gulf of Mexico. Gulf Coast Assoc Geol Soc Trans 38:535-541

Schroepfer RL, Szedlmayer ST (2006) Estimates of residence and site fidelity for red snapper Lutjanus campechanus on artificial reefs in the northeastern Gulf of Mexico. Bull Mar Sci 78:93-101

SEDAR (Southeast Data, Assessment, and Review) (2005) SEDAR 7, Gulf of Mexico red snapper complete stock assessment report. SEDAR, Charleston, SC

Shipp RL, Bortone SA (2009) A prospective of the importance of artificial habitat on the management of red snapper in the Gulf of Mexico. Rev Fish Sci 17:41-47

Simpfendorfer CA, Heupel MR, Hueter RE (2002) Estimation of short-term centers of activity from an array of omnidirectional hydrophones and its use in studying animal movements. Can J Fish Aquat Sci 59:23-32

> Simpfendorfer CA, Huepel MR, Collins AB (2008) Variation in the performance of acoustic receivers and its implication for positioning algorithms in a riverine setting. Can J Fish Aquat Sci 65:482-492

Starr RM, Heine JN, Felton JM, Cailliet GM (2002) Movements of bocaccio (Sebastes paucispinis) and greenspotted (Sebastes chlorostictus) rockfishes in a Monterey submarine Canyon: implications for the design of marine reserves. Fish Bull 100:324-337

Strelcheck AJ, Cowan JH Jr, Patterson WF III (2007) Site fidelity, movement, and growth of red snapper: implications for artificial reef management. In: Patterson WF III, Cowan JH Jr, Fitzhugh GR, Nieland DL (eds) Red snapper ecology and fisheries in the U.S. Gulf of Mexico. Am Fish Soc Symp 60:147-162

Summerfelt RC, Smith LS (1990) Anesthesia, surgery, and related techniques. In: Schreck CB, Moyle PB (eds) Methods for fishery biology. American Fisheries Society, Bethesda, MD, p 213-272

Szedlmayer ST (1997) Ultrasonic telemetry of red snapper, Lutjanus campechanus, at artificial reef sites in the northeast Gulf of Mexico. Copeia 1997:846-850

Szedlmayer ST (2007) An evaluation of the benefits of artificial habitats for red snapper, Lutjanus campechanus, in the northeast Gulf of Mexico. Proc Gulf Caribb Fish Inst 59:223-229

Szedlmayer ST, Schroepfer RL (2005) Long-term residence of red snapper on artificial reefs in the northeastern Gulf of Mexico. Trans Am Fish Soc 134:315-325 
Szedlmayer ST, Shipp RL (1994) Movement and growth of red snapper, Lutjanus campechanus, from an artificial reef area in the northeastern Gulf of Mexico. Bull Mar Sci 55:887-896

Tolimieri N, Andrews K, Williams G, Katz S, Levin PS (2009) Home range size and patterns of space use by lingcod, copper rockfish and quillback rockfish in relation to diel and tidal cycles. Mar Ecol Prog Ser 380:229-243

Topping DT (2009) The use of ultrasonic telemetry to estimate residency, movement patterns, and mortality of red snapper, Lutjanus campechanus. PhD dissertation, Auburn University, Auburn, AL

Topping DT, Lowe CG, Caselle JE (2005) Home range and habitat utilization of adult California sheephead, Semicossyphus pulcher (Labridae), in a temperate no-take marine reserve. Mar Biol 147:301-311

Topping DT, Lowe CG, Caselle JE (2006) Site fidelity and seasonal movement patterns of adult California sheephead Semicossyphus pulcher (Labridae): an acoustic monitoring study. Mar Ecol Prog Ser 326:257-267

Turpin RK, Bortone SA (2002) Pre- and post-hurricane assessment of artificial reefs: evidence for potential use as refugia in a fishery management strategy. ICES J Mar Sci 59:S74-S82

Wakeman JM, Arnold CR, Wohlschlag DE, Rabalais SC

Editorial responsibility: Nicholas Tolimieri,

Seattle, Washington, USA
(1979) Oxygen consumption, energy expenditure, and growth of red snapper (Lutjanus campechanus). Trans Am Fish Soc 108:288-292

Watterson JC, Patterson WF III, Shipp RL, Cowan JH Jr (1998) Movement of red snapper, Lutjanus campechanus, in the north central Gulf of Mexico: potential effects of hurricanes. Gulf Mex Sci 1998:92-104

Wells RJD, Cowan JH Jr (2007) Video estimates of red snapper and associated fish assemblages on sand, shell, and natural reef habitats in the north-central Gulf of Mexico. In: Patterson WF III, Cowan JH Jr, Fitzhugh GR, Nieland DL (eds) Red snapper ecology and fisheries in the U.S. Gulf of Mexico. Am Fish Soc Symp 60:39-57

Westmeyer MP, Wilson CA III, Nieland DL (2007) Fidelity of red snapper to petroleum platforms in the northern Gulf of Mexico. In: Patterson WF III, Cowan JH Jr, Fitzhugh GR, Nieland DL (eds) Red snapper ecology and fisheries in the U.S. Gulf of Mexico. Am Fish Soc Symp 60: 105-121

Wilson CA, Nieland DL (2001) Age and growth of red snapper, Lutjanus campechanus, from the northern Gulf of Mexico off Louisiana. Fish Bull 99:653-664

Zeller DC (1997) Home range and the activity patterns of the coral trout Plectropomus leopardus (Serranidae). Mar Ecol Prog Ser 154:65-77

Submitted: May 3, 2011; Accepted: July 11, 2011

Proofs received from author(s): September 7, 2011 